\title{
Sustainable housing development: role and significance of satisfaction aspect
}

\author{
Iman Abdelshahid Ibrahim*
}

\begin{abstract}
Providing quality public housing is one of the main goals of the United Arab Emirates (UAE) government. This paper assesses the level of satisfaction with public housing offered by the UAE government to its citizens based on the physical characteristics and traditional social aspects of the housing unit, urban design, and social environment in the residential area, whereas also their contribution to the residents' life quality under overall satisfaction with the place of living. At the same time, the study provides access to sustainability measurements applied at both the environmental and social levels within the Estidama accredited national rating system. The survey results of two residential complexes in Abu Dhabi show that the majority of residents are mostly satisfied, although the overall level of satisfaction with the functionality of the building and public facilities provided was generally higher than that related to the social environment in the residential district. The research focused on the application of new technologies that increase the level of sustainability in future housing projects.
\end{abstract}

Keywords: Estidama, Green building, Public housing, Residential satisfaction, UAE, Urban sustainability

\section{Introduction}

Housing improvement is one of the most important sectors of the economy, which ensures the prosperity of urban development and sustainability (Rahman et al. 2018). The variety of design solutions and innovative technologies incited a lot of challenges in the quality of accommodation and satisfaction of residents. Often, designers strive to maintain the aesthetics of housing appearances and neglect the actual needs of clients (Lopez 2010). Compared to commercial buildings, the residential design must correspond to day-to-day concerns of people's lives and address problems related to their life experience and ambience (Anderson 2016). Besides, due to excessive energy consumption, housing construction must be sustained (Roufechaei et al. 2014). Thus, for successful sustainable housing development, an optimal balance between sustainable housing and customer satisfaction is required (Chan and Adabre 2019).

*Correspondence: iibrahim@sharjah.ac.ae

Department of Applied Design/Interior Design, University of Sharjah, Sharjah, UAE
In the Middle East, the United Arab Emirates (UAE) strives to consistently develop the urban construction industry through the creation of sustainable cities using innovative technologies that would be consistent with overall state expansion and growth over the years. To this effect, green building norms and regulations have been introduced in Abu Dhabi and Dubai, such as the national Estidama Pearl program, which was launched in 2010 by the Department of Urban Planning and Municipalities in Abu Dhabi (Awadh 2017). This program includes a Pearl Rating System (PRS), which ensures the sustainability of housing throughout its life cycle from design to construction and operation (Alobaidi et al. 2015). The rating system with a scale from 1 to 5 Pearl focuses on the construction of residential buildings and villas to the different individual requirements to improve the sustainability of the built-up environment. The developed requirements should contribute to minimizing water and energy consumption, improving waste recycling, and using local environmentally friendly materials for construction. The design of buildings must meet a minimum rating of 1 (Pearl 1) and, for public housing, this minimum is 2 (Pearl 2). 
In the UAE, much attention and funding are given to the development of public or social housing. At present, the Ministry of Public Works and Housing and Sheikh Zayed's Housing Program, as well as local social housing agencies, are dealing with the problems of providing state accommodation (Ahmed 2017). The goal of these federal organizations is to provide decent housing with a large number of subsidies that meets the requirements of all citizens and is aimed at building entire neighbourhoods following the principles of traditional, functional, and autonomous models of urban sub districts (Patricios 2002). In Abu Dhabi, such projects as Ain Al Faydah, Watani, Jebel Hafeet, Al Falah, and others have been developed and implemented through support from government investments.

These complexes are residential neighbourhoods consisting of villas and houses and related administrative and commercial buildings, mosques, schools, and parks. These properties have been designed following the traditional planning of sub districts and villages in mind. The main task in the design was to combine conventional architecture and innovative technologies through an optimal balance. The results of a study on sustainable social housing in the city of Al Ain (Ahmed 2017) showed that traditional principles of neighbourhood planning and design are less effective for residents as local communities may have different cultural and social development needs. According to the author of the article, it is community residents who can regulate the sustainability of urban forms by giving preference to one tendency over another.

The purpose of this study was to assess the level of satisfaction with public accommodation facilities offered by the UAE government to citizens based on the physical characteristics and traditional social aspects of the housing unit, urban design, and social environment in the residential area, whereas also their contribution to residents' life based on general social and cultural satisfaction with housing. For this purpose, the following research objectives should be fulfilled:

1. To assess the level of satisfaction of UAE citizens and sustainability parameters in residential models and housing complexes in the state housing stock;

2. To evaluate the application of environmental, social, and economic sustainability in public housing construction and its compatibility with the social needs of citizens considering the culture of the Emirates;

3. To determine the sustainability assessment system for public housing construction, Estidama, and how it fits the nature of the project;

4. To evaluate the community's ability to apply the postsettlement evaluation to housing estates and the extent to which the program interacts with the evaluation to achieve the best possible outcome.

The analytical assessment of residential complexes in terms of environmental, social, and economic sustainability can enable setting particular standards in design that should be followed in new projects to ensure increased sustainability. Besides, it allows developing recommendations for future projects to be followed for a higher level of residential conditions in the state housing stock through sustainability evaluation.

\section{Literature review}

As stated above, in projecting housing complexes, the housing design should represent social, aesthetic, and environmental concepts and include all elements for creating an interior space that would satisfy the lifestyle of people or community (Dohr and Portillo 2011). Satisfaction with residency is one of the most important aspects that affect the quality of life (Walton et al. 2008) and the very behaviour of people in living spaces (Sakip et al. 2012). The satisfaction of residents is based on personal qualities (cognitive, emotional, or behavioural characteristics) and social characteristics of the living environment (Mohit and Nazyddah 2011). Thus, social, economic, and environmental aspects of housing design should be considered in order to achieve maximum effect (Ali 2010; Karji et al. 2019). It can be achieved by respecting the cultural, psychological, physiological, financial, and historical characteristics and preferences of residents or the community.

However, along with satisfying these basic needs of residents, other aspects such as security and social status are also highly relevant. According to Shach-Pinsly (2019), in urban areas that are free from crimes and strife, people feel safer when interacting with others, resulting in increased trust and reciprocity among residents and enhanced feelings of community and belonging. Besides, these social interactions in a community build good relations between residents (Hussein 2019) and a sense of pride in belonging to that community (Kohon 2018). Another important aspects are the identity and comfort of urban life through environmental design and developed infrastructure (Shawket 2018).

Nowadays, in addressing the issue of upgrading the life quality, a healthy environment is given more priority by improving socio-economic and environmental conditions for present and future generations (Dizdaroglu and Yigitcanlar 2016). Sustainable development is about meeting human needs and improving their quality of life by minimizing the negative impact on the environment (Ingrao et al. 2018; Ioppolo et al. 2019). Since public places in neighbourhoods are designed for communication and 
recreation, the well-being of their residents can also serve as an indicator of satisfaction with the urban surrounding and a better quality of life (Van Kamp et al. 2003). These places include playgrounds for children, parks, walking trails, monuments, and architectural structures. According to Saiedlue et al. (2015), the presence of water elements (lakes, fountains) and the abundance of green spaces are fundamental to increasing satisfaction through refreshing and purifying the environment and, thus, providing significant health benefits to residents.

In addition to the environmental and social components of living satisfaction, the development of infrastructure and economic factors are also of high importance. A sense of identity, belonging, and comfortable city life arises from such elements in urban design as points of key services used by residents regularly (Dempsey et al. 2011). The latter include doctors and post offices, banks, supermarkets or stores on the corner, schools, preschool facilities, libraries, sport and entertainment complexes, restaurants and cafes, community centers, and others. All of these elements preferably must be located in places equally accessible to residents and guests. Besides, the transport interchange should meet the needs of all participants (pedestrians, cyclists, and car drivers), whereas also the availability of entrances for people with physical disabilities and various types of municipal transport should be on a high level.

Thus, to study the impact of various aspects on the residency comfort is necessary for a better understanding of what initiatives to be taken to improve the sustainability parameters in residential models and complexes of the state housing stock. The paper (Liu 2003) presents the results of assessing the quality of housing projects by estimating the level of satisfaction of residents. It was shown that despite the observance of technical and engineering aspects in the development of large housing complexes, more success of the project is expected with the cooperation and coordination between designers and other parties involved (Liu 2003; Lee and Park 2010; Mohit and Nazyddah 2011). Ultimately, each residential project is implemented for accommodation, and, therefore, a dialogue between the parties is important in the design process as it allows for a proper understanding of the political and social responsibility of the state (Liu et al. 2011; Lichtenstein et al. 2013).

Besides, the assessment of the final housing option provides important information on the degree of satisfaction with the needs, demands, and expectations of residents (Wongbumru and Dewancker 2016). Also, the study (Teck-Hong 2012) demonstrates how demographic and socio-economic factors influence the level of satisfaction. For example, older people are usually more enjoy their household than young ones (Wagner et al. 2010), homeowners are more gratified than apartment owners (Al-Momani 2000), and also the fact ownership and rent can affect the level of satisfaction (Riazi and Emami 2018). All of the above-mentioned factors and characteristics are accounted for in developing a conceptual model for satisfaction assessment, and some aspects are taken as units of measure. The following section discusses the elements that will be used to measure the satisfaction degree. They also form the basis for the development of a data collection tool.

\section{Materials and methods \\ Case study area}

This research is devoted to studying the level of satisfaction with the principles of sustainable urban development on the example of two public housing districts of the UAE, located in the Emirate of Abu Dhabi. The first site of $\mathrm{Al}$ Ain Faydah is located in $\mathrm{Al}$ Ain city near mount Jebel Hafeet. It covers an area of 4.12 million $\mathrm{m}^{2}$ and contains 2000 villas with entertainment, educational, and cultural facilities integrated into the development (Fig. 1).

This project is aimed at recreating the community of Faridj (traditional region of the Emirates), where villas are grouped around a common open space. The architectural design of the facades applied to the Spanish and Mediterranean style (Fig. 2). Each villa with a total area of $382 \mathrm{~m}^{2}$ contains five bedrooms, a maid's room, a living and dining room, a Majlis, a kitchen, a laundry room, and bathrooms. More than 12,000 residents can reside in this complex. The first phase of construction according to the general plan (Fig. 1) was fully implemented and the project was introduced into operation in 2015 (Plan Al Ain... 2015).

The Al Watani housing complex located in Khalifa City A in the Emirate of Abu Dhabi was chosen as the next object for research (Fig. 3). It covers a total area of 1.85 million square meters and offers 1.390 villas and 50 houses with 2.500 apartments to satisfy local housing needs. The project represents a complex configuration of public facilities supported by an appropriate infrastructure that includes schools, stores, and public open spaces to establish communication centers and local meetings.

As follows from Fig. 3, only the first stage of this project has been completed, and 400 villas were commissioned in 2015. The design of each villa is in the style of traditional architecture, which perfectly matches modern design tendencies through modern materials and technology (Fig. 4).

The total area of each villa is $405 \mathrm{~m}^{2}$, which includes four or five bedrooms, a Majlis, a kitchen, bathrooms, garages, maids' facilities, and other necessities for the average Emirati family (Watani Housing Project 2015). 


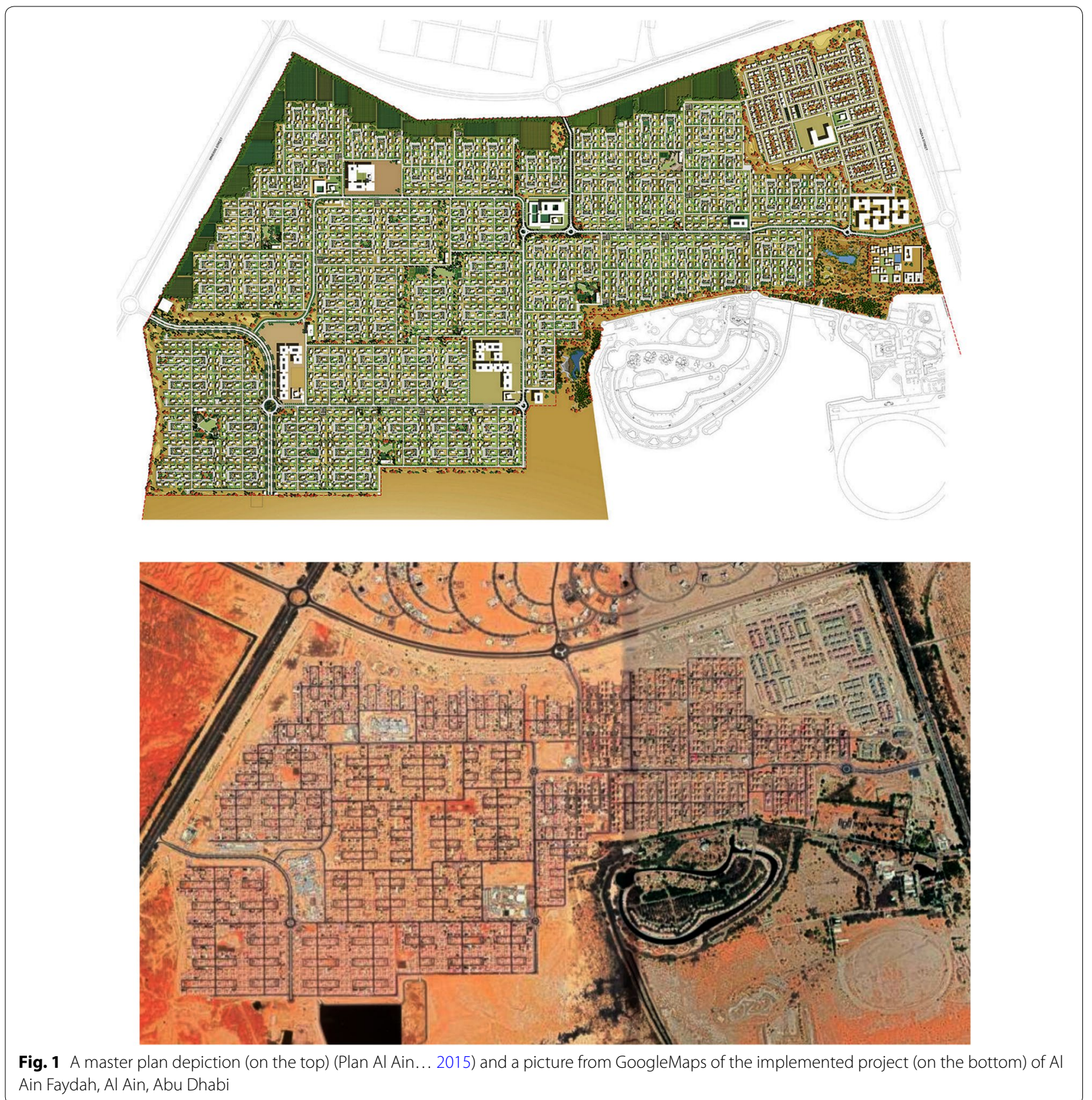

\section{Concept model of measuring the satisfaction level}

Figure 5 presents a schematic representation of the conceptual model for assessing the level of satisfaction in residents, which includes four different influencing factors and parameters. According to Ogu (2002), it implies the satisfaction with the design and architecture of the house (1), the functionality of the house (2), the level of accessibility (3), and the district location and community (4). These parameters include expectations, socio-economic dynamics, and demographic data.
Each factor has a particular designation. For example, the first factor includes the degree of satisfaction with the physical attributes of the house, such as the architecture of the building, the selected design, and interior content, i.e., the layout, number, and size of rooms, the presence of terraces, gardens, or green areas, etc. The second factor (functionality of the house) is the degree of satisfaction with the performance of the house components like windows, doors, roof, floor, wall thickness, noise insulation, the location of water and air conditioning 


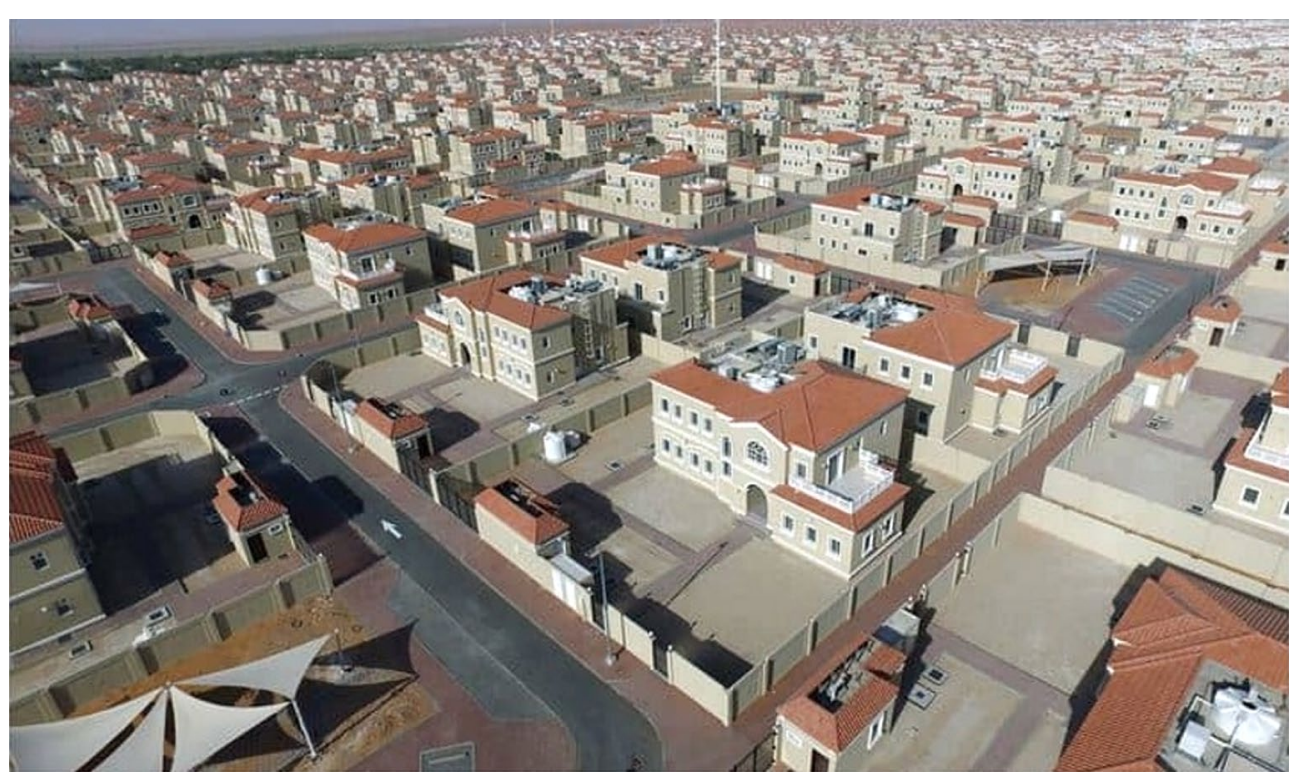

Fig. 2 Al Ain Faydah district of the UAE Public Housing Fund

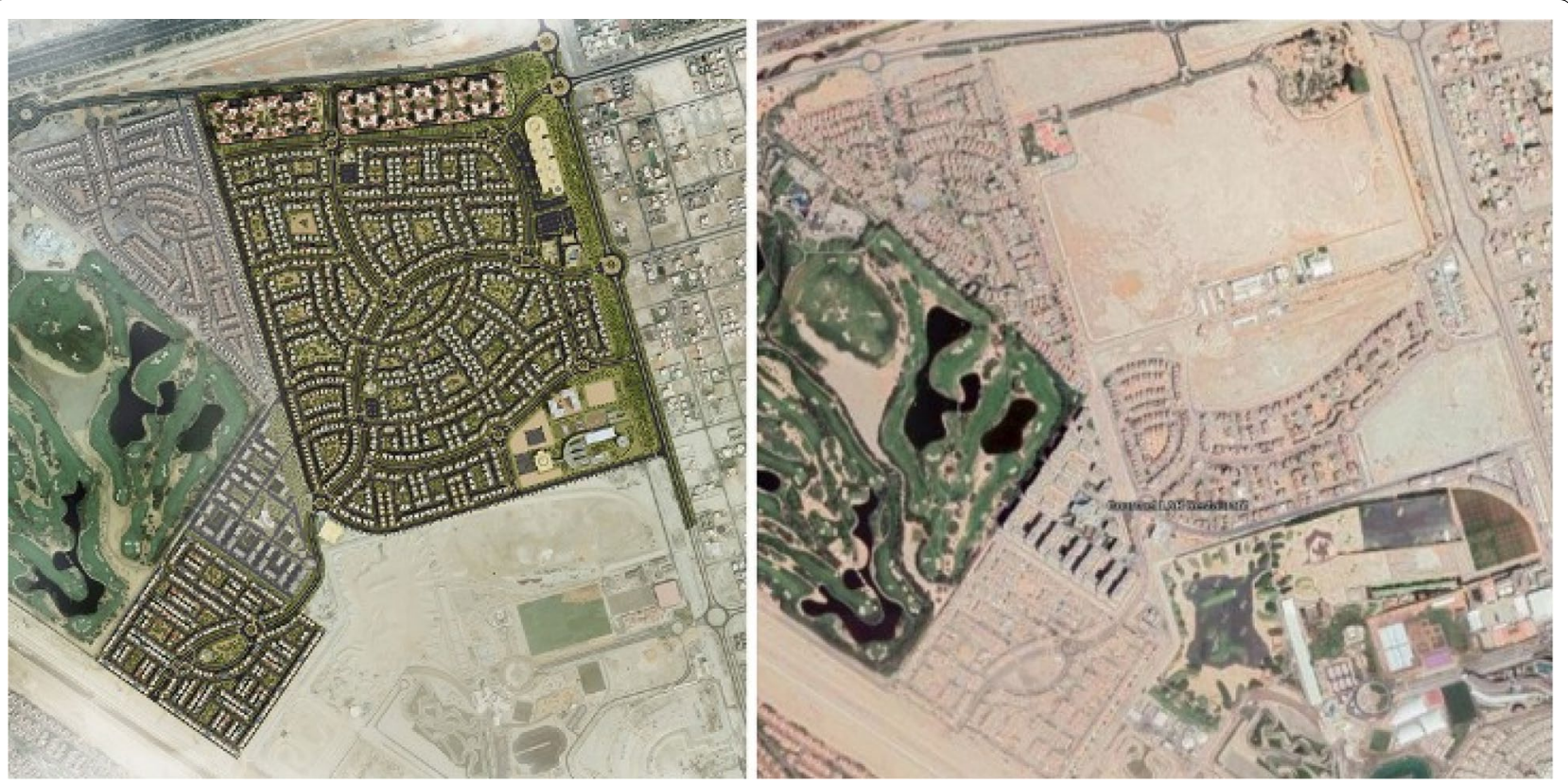

Fig. 3 A masterplan depiction (on the left) (Watani Housing Project 2015) and Google Maps picture of the implemented part of the project Al Watani, Khalifa City A, Abu Dhabi (on the rights)

communications, ventilation and air filtration, etc. Thus, these two factors are attributed to the satisfaction of the basic physiological and emotional needs of residents. The remaining factors are related to socio-economic aspects.

Also, the accessibility factor in a broader sense refers to the level of satisfaction with the availability of necessary services, namely, school, garden, clinic, stores, sports grounds or health centers, public places and mosques, etc. This factor may also include traffic interchange and the availability of municipal transport. The last satisfaction factor refers to the affiliation to a particular location and community, as well as the level of technical service. Attributes here are public places, street conditions, lighting levels, roads and sidewalks, population density and 


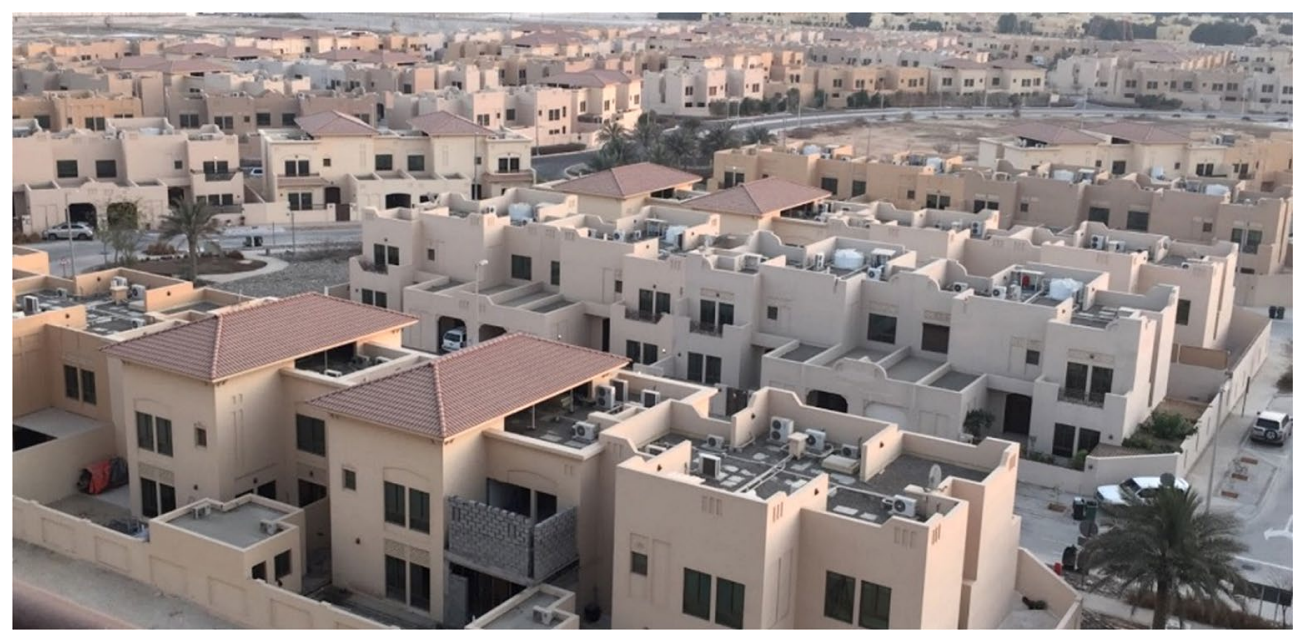

Fig. 4 The AI Watani district of the UAE public housing fund

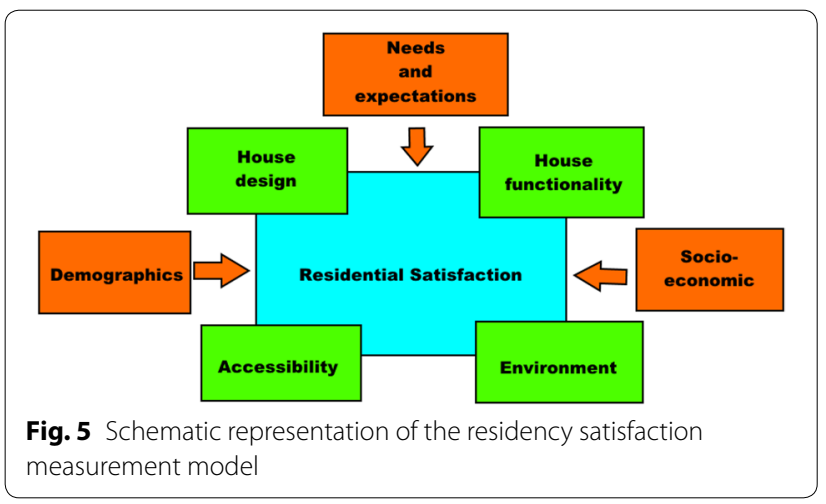

traffic congestion, etc. All these designations were used in the development of questionnaires to fully measure and comprehensively analyze the level of satisfaction with residency in public housing, and identify negative factors that can be addressed in future projects.

\section{Questionnaire development and data collection}

Based on the conceptual model of satisfaction measures described above, a comprehensive questionnaire was developed to determine socio-economic and physical characteristics, environmental parameters, and other key variables. A total of 26 variables were selected, and 26 questions were compiled, which included open questions and those to be assessed on a five-point Likert scale or the Guttman scale. The open question assumes a free answer for the respondent to identify their attitude towards the problem at hand and to collect their opinions on the project, suggestions for improving the current conditions to increase the number of variables in future questionnaires, whereas also new parameters and problems related to housing. Since the satisfaction level was measured using these scales, descriptors were developed for the Likert scale to consider extreme, moderate, and neutral responses such as 'very dissatisfied,' 'dissatisfied,' 'neutral,' 'satisfied', and 'very satisfied.'

Questionnaires were developed and polled via social media networks in special groups created for residents in particular applications. The survey was also sent to email addresses of those respondents, who were not registered in any of the social media networks. The proposed questionnaire is presented in Appendix A. In total, the survey was attended by 746 participants, of which 544 were residents of $\mathrm{Al}$ Ain Faydah and 202 of $\mathrm{Al}$ Watani residential complexes. Since in these housing areas include a total of 17,000 residents, a population sample of $10 \%$ was sufficient to obtain an adequate estimate for the survey (Higley 2008). The responses were collected over 2 months (2019 October-November).

\section{Data processing techniques}

The survey results were entered into the database and processed using the SPSS Statistics software package. The Likert scale values for each factor were used to calculate the Z-point index following the formula:

$$
Z_{n j}=\left(Y_{n j i}-\tilde{y}_{n}\right) / S_{n}
$$

where $\mathrm{n}$ is the value of the factor from 1 to 4 points, $\mathrm{j}$ is the ordinal number of the respondent (from 1 to 746), $Y_{i}$ is the observed evaluation of each house for $n$ factor, $\tilde{y}_{n}$ is the average distribution for $n$ factor, and $S_{n}$ is the standard deviation of $\mathrm{n}$ factor for all residents. When calculating the $\mathrm{Z}$ index, residents were grouped into satisfaction categories based on standard deviation (SD). The Z-values for each home represents the degree of 
satisfaction relative to all residents participating in the survey (Table 1).

The data presented in the table demonstrate that tenants with negative Z-values are classified as unsatisfied, while those with positive $Z$-values are considered satisfied. The Z Z-values in the middle of the distribution is classified as moderately satisfactory and associated with some uncertainty. Thus, the value can turn negative if the housing conditions worsen, otherwise, the Z-value remains positive. In addition to $(\mathrm{Z})$ indicator, a satisfaction index (IS) was introduced, which is expressed as a percentage of the maximum score given by the resident for each factor.

These factors, in turn, were subdivided into satisfaction categories. As with Z-index, the IS-index has five categories: very low (20-34\%), low (35-49\%), medium (50-64\%), high (65-79\%), and very high (80-100\%). In calculations, each point on the Likert scale was multiplied by 20 (Watani Housing Project 2015). As illustrated, the satisfaction index varies between 20 and 100\%, where the average value corresponds to $60 \%$. Thus, scores above $60 \%$ suggest an area of medium/high satisfaction level, and the level below $60 \%$ indicates an area of medium/low satisfaction. Percentage ranges of satisfaction will be used in the analysis. The second indicator of satisfaction efficiency was the variable index $\left(I_{v}\right)$, which determines the extent to which each variable affects the level of satisfaction among residents and is calculated as follows (Watani Housing Project 2015):

$$
I_{\nu}=\frac{\sum_{t=1}^{N} y_{t}}{\sum_{i=1}^{N} Y_{i}} \cdot 100 \%
$$

where $y_{t}$ is an estimate for variable $t$ for $n$ factor. Four classification types of satisfaction levels were chosen for $I_{v}$, which correspond to the following ranges: positive (70-100\%), moderately positive (60-69\%), moderately negative (50-59\%), and negative (20-49\%).

Given the fact that overall satisfaction is not considered a simple variable, the combination of satisfaction index

\section{Table 1 Satisfaction categories based on Z-value with SD}

\begin{tabular}{llll}
\hline $\begin{array}{l}\text { Satisfaction } \\
\text { level }\end{array}$ & $\begin{array}{l}\text { Range } \\
\text { of Z-values }\end{array}$ & $\begin{array}{l}\text { Category } \\
\text { of satisfaction } \\
\text { level I s }\end{array}$ & $\begin{array}{l}\text { Range } \\
\text { of satisfaction } \\
\text { index Is }\end{array}$ \\
\hline $\begin{array}{l}\text { Highly dissatis- } \\
\text { fied }\end{array}$ & $Z<-2$ & Very low & $20-34 \%$ \\
$\begin{array}{l}\text { Dissatisfied } \\
\begin{array}{l}\text { Moderately satis- } \\
\text { fied }\end{array}\end{array}$ & $-2 \leq Z \leq-1$ & Low & $35-49 \%$ \\
$\begin{array}{l}\text { Satisfied } \\
\text { Highly satisfied }\end{array}$ & $Z \geq 2$ & Average & $50-64 \%$ \\
\hline
\end{tabular}

variables corresponding to factors 1-4 (Fig. 5) is assumed to provide a more reliable assessment of overall satisfaction. Thus, the overall satisfaction index will be calculated as an average of four factors. A comparative and qualitative analysis was performed for these two projects. Also, the values of the Estidama Pearl rating system and the satisfaction level accepted for this project were compared with the data obtained for the described projects.

Building ratings according to Estidama Pearl Rating System are assigned as follows: 1 Pearl (20 mandatory conditions), 2 Pearls (20 mandatory conditions +60 credit points), 3 Pearls (20 mandatory conditions +85 credit points), 4 Pearls ( 20 mandatory conditions +115 credit points), and 5 Pearls (20 mandatory conditions +140 credit points). In the Pearl Building Rating System (PBRS) v1.0, eight credit categories with a maximum of 180 points (Abu Dhabi and urban planning council 2010) are available, which are depicted in Fig. 6.

Mandatory loans must be fulfilled by each project applying for Pearl 1 rating. As follows from above, all state-funded projects should be rated with 2 Pearl, and, therefore, 60 additional points should be added to the mandatory requirements. These points can be achieved through the use of innovative technologies, circular water supply systems, renewable energy, waste minimization, etc. Therefore, tracking the impact of the rating program used on the level of satisfaction in residents and the quality of their life is of high importance.

\section{Results and discussion}

Survey processing results showed that $85 \%$ of the respondents were working people. Besides, statistical analysis of the demographic situation in the surveyed areas has good dynamics towards increasing the number of residents (Fig. 7).

As follows from Fig. 7, the average number of family members living in a villa is $5-6$ people, including $2-3$ children on average, which is quite suitable for the living area of the villa. According to the analysis results, the average age of children living in these complexes was 5-7 years, which indicates that the surveyed tenants are quite young. Analysis of demographic data for the Watani complex showed similar results. Thus, these results indicate an emerging need for public places and educational institutions for children within the complex. The overall level of satisfaction per capita is shown in Fig. 8.

Hence, $41.8 \%$ of Al Ain Faydah complex residents consider their overall satisfaction to be high and medium. Nearly similar indicators were obtained in the survey of the Al Watani residential complex, where $40 \%$ of residents estimate their level of satisfaction to be medium and high. Besides, indicators of the low and very high levels of satisfaction are almost the same, which indicates 


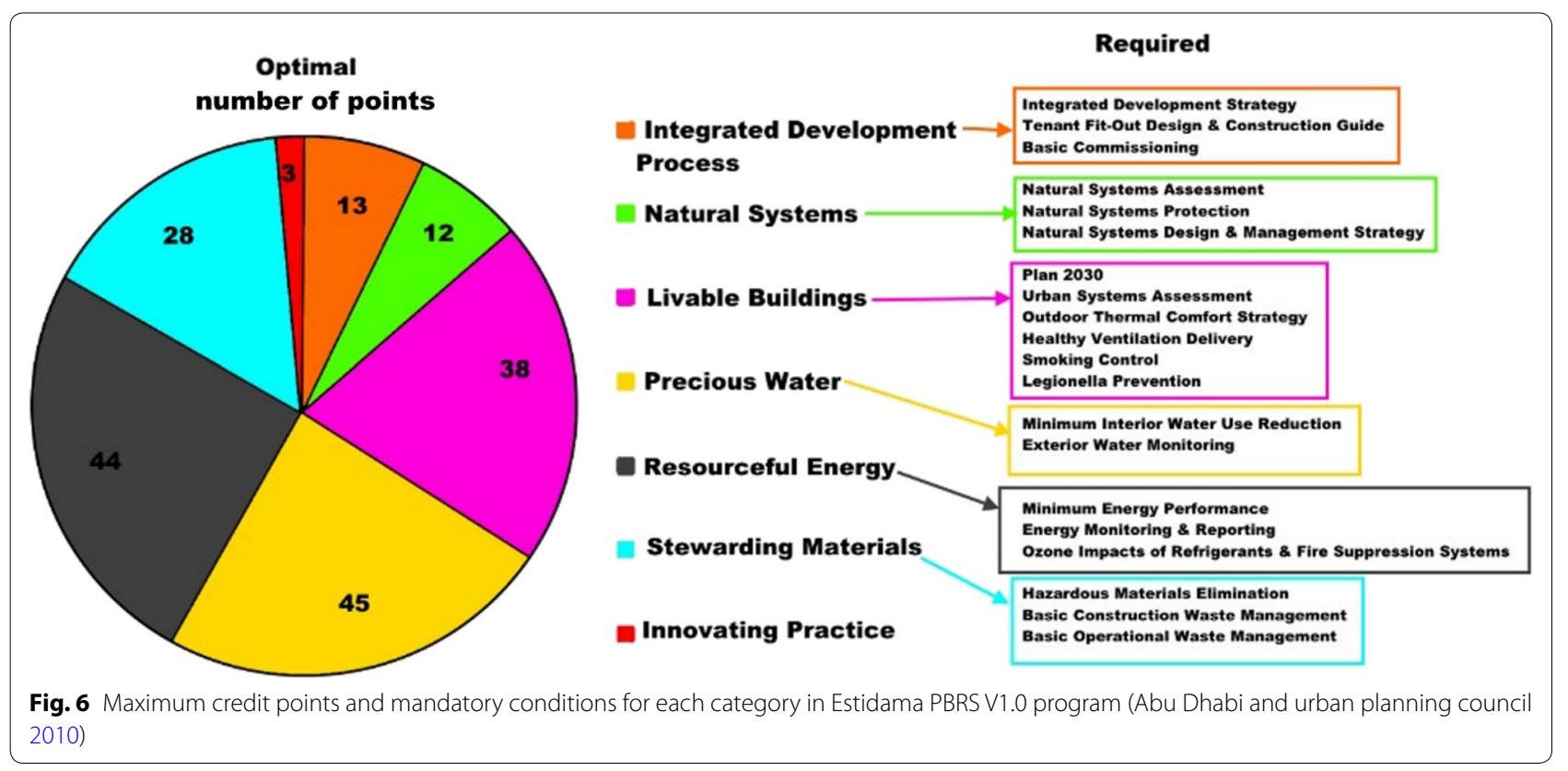

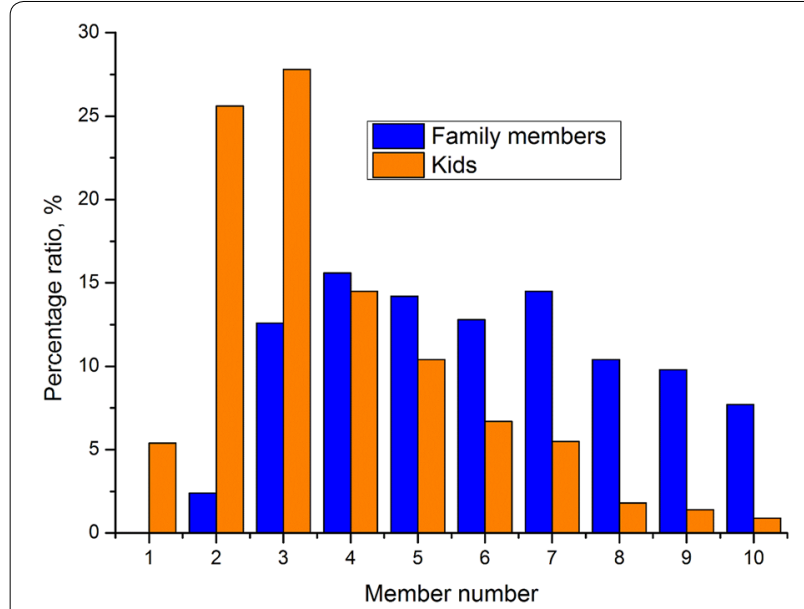

Fig. 7 Results of a demographic study of the Al-Ain Faydah residential area

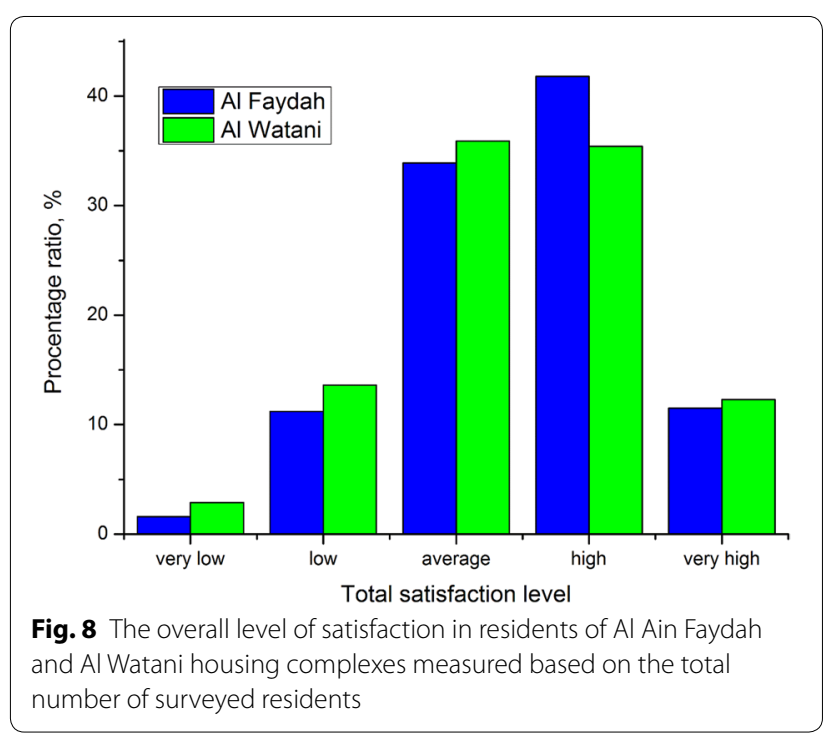

moderate positive and negative levels in equal degrees. The maximum number of residents of $\mathrm{Al}$ Ain Faydah (61\%) consider the functionality of the house as a moderately positive, i.e., the layout, choice of materials, water supply, and comfortable location of internal communications. Also, $38-47 \%$ of residents refer to other factors that influence satisfaction. Thus, almost half of the interrogated residents of the $\mathrm{Al}$ Ain Faydah are moderately satisfied with their living conditions (60-69\% satisfaction index), which is in good agreement with indicators of overall satisfaction level (Fig. 8). 


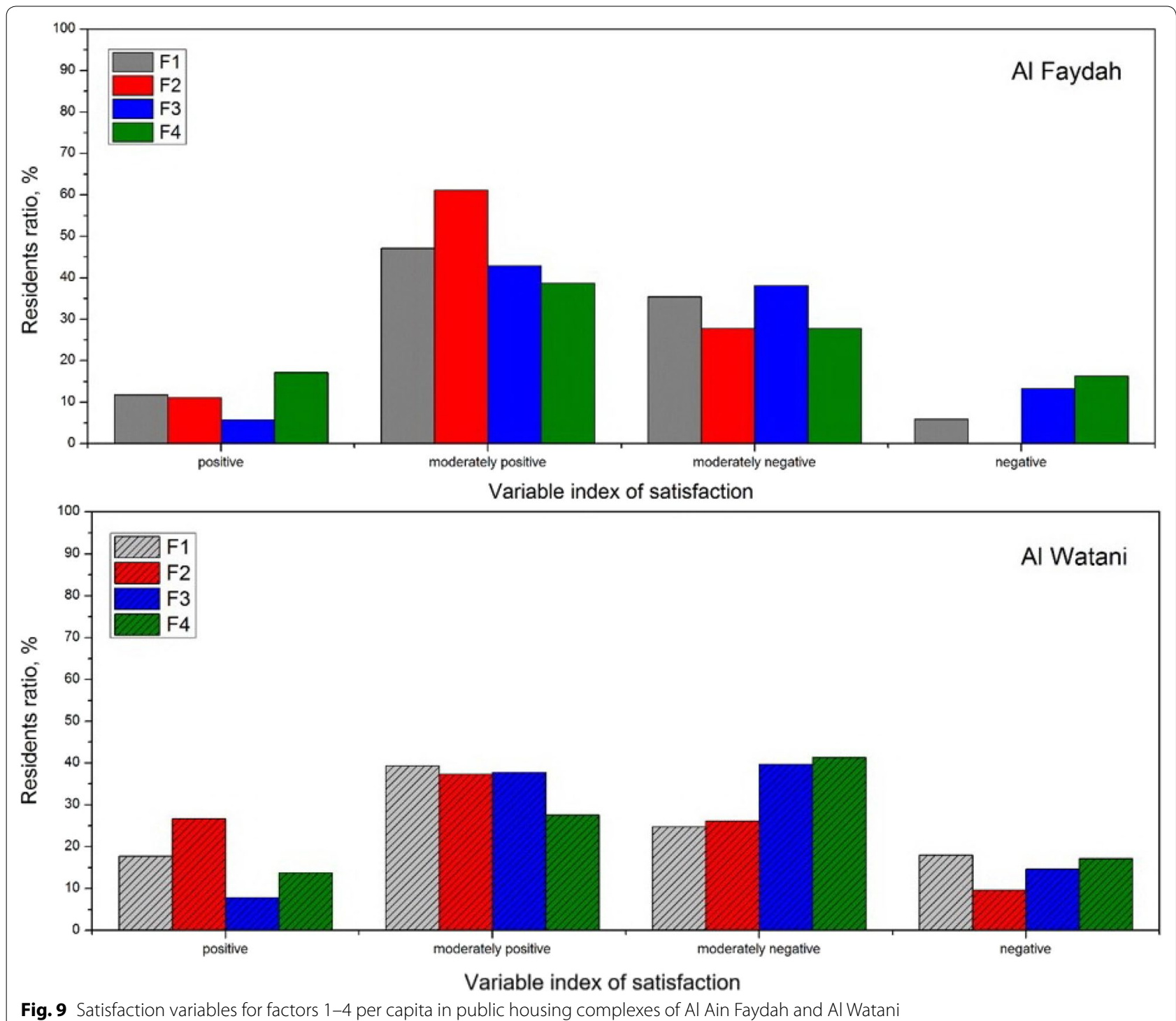

Slightly less of the interrogated residents (26-35\%) have a moderately negative attitude to living in this complex, which corresponds to the average satisfaction level presented in Fig. 7. Besides, the same percentage of residents (11-12\%) have an extremely negative attitude towards the location and community. Based on the data obtained for the Al Ain Faydah project, the satisfaction level is more influenced by the factors of functionality and design of the house, i.e., meeting the physiological needs and environmental parameters, as compared to socio-economic parameters, which correspond to higher levels of unsatisfaction. This may be due to the location of villas relative to each other and the territorial location of public and entertainment places. Also, some residents noted their dissatisfaction with the noise and the resulting garbage near their homes due to the renovation works of nearby villas, which is a significant issue in new areas.

The analysis results of the Al Watani residents' poll showed that they estimate this complex as moderately negative and moderately positive depending on the factor. The maximum number of residents $(41.4 \%)$ expressed moderately negative satisfaction (50-59\%) in terms of the district location and community. Such high values of dissatisfaction may be due to the incompletion of the project, where most of the territory is still under construction. Besides, many priority service delivery points specified in the project have not been completed yet. However, $37-39 \%$ of residents are quite 
satisfied with the design, functionality, accessibility, and location of the houses.

It may also be noted that $18 \%$ of the population is $70-100 \%$ satisfied with the functionality of the houses, which plays a key role as in the case of Al Ain Faydah complex. Among negative indicators, $17-18 \%$ of residents are not satisfied with the design of houses and the availability of public spaces. As mentioned earlier, this complex has been maintained in a traditional style and has a smaller open space area, and the curvature of the streets may contribute to some sense of discomfort and constraint individual space. The assessment results obtained for the Al Watani complex show that the developed housing project is moderately satisfactory for living from the point of view of residents, which is a positive characteristic for further construction.

As for the analysis of how each factor and variable affects the level of satisfaction individually, most of the interviewed population were more satisfied $(>70 \%)$ with the design and layout and level of security, as well as the presence of spacious rooms that give a sense of comfort and privacy. A larger number of respondents gave high scores on questions about feeling of comfort and time in their home, indicating a high degree of satisfaction with physiological and psychological needs. These factors are mandatory requirements in the Estidama program, which fully meet the expectations of residents. In terms of architecture and functionality of houses, the study showed that $49-60 \%$ of residents are highly satisfied with the overall condition of their house. The majority of respondents $(80 \%)$ answered negatively to the question about the modification of the house, which indicates a multifaceted approach to the physiological and aesthetic characteristics of living. Besides, residents gave more positive answers to the rational design of the roof and windows, which led to the rare use of tight curtains and the ability to air the room naturally in good weather.

The factor of accessibility corresponded to a moderate level of satisfaction according to the opinion of $40-42 \%$ of residents. This level is associated with complicated access to medical facilities and safety in public places. Most respondents gave low scores to these questions. However, other variables that relate to green areas, children's playgrounds, and sports grounds were estimated with high scores. Given the presence of 2-3 children in each home, this need for separation and the physical health of children was met to a high degree. In terms of access to schools, the respondents' opinions differed greatly, which disabled the determination of the satisfaction tendency.

Most respondents indicated that they were generally satisfied with the quality of life in these complexes. Residents appreciated the location and layout of their villas, as well as the large area of parks and green spaces. Poor salt isolation in some buildings in the Al Watani and a road junction in the settlement were mentioned as negative aspects. Concerning the $\mathrm{Al}$ Ain Faydah, respondents noted the distance from the city's business center, which takes time to travel to work, and the lack of entertainment and recreational areas. Residents also pointed out that they were very satisfied with their neighbors in terms of their relations, sympathy, and confidentiality.

The results of a survey of residents' satisfaction showed that government housing projects can be considered an acceptable place for a comfortable life with a high and average level of satisfaction, which fully meets the needs in terms of physiological, social, economic, and environmental characteristics. Assessment scales from Abu Dhabi and urban planning council (2010) were used to calculate the approximate Estidama rating indicators for these housing complexes. The results of a rough estimation on the proposed scales in the Estidama PBRS V1.0 program showed that both complexes are gaining enough additional credits (above 60) to obtain the Pearl 2 rating. The percentage of points on the proposed categories is shown in Fig. 10.

The figure depicts how categories of residential buildings, resource energy, materials management including application of environmentally friendly substances in construction and internal works, and the use of energyefficient technologies with lower emissions of harmful substances influence the rating level. Besides, another important aspect is the use of local, secondary, and biodegradable materials in construction and decoration, as well as waste management and its sorting. Valuable water management greatly contributes to the rating points as well.

According to the master plan, these complexes are equipped with systems to reduce water consumption and sensors on internal and external facilities to control water flow and leakages. Thus, roughly assessing housing against the rating system, it can be characterized as a fairly accurate complex for sustainable housing development. However, this assessment does not guarantee that all conditions at all stages of construction will be met, as it depends on many factors, including the choice of contractors and technological solutions. Nevertheless, for the complexes under study where people live, this system has fully met its expectations, which affects the level of satisfaction of residents with public housing.

Findings obtained in the course of research agree with the results of other works. Thus, the paper (Howley et al. 2009; Buys and Miller 2012) modeled and quantitatively and qualitatively evaluated the relationship between residence density and satisfaction with the neighbourhood in central city districts. The study shows that a high density of residents has a negative impact on the level of 


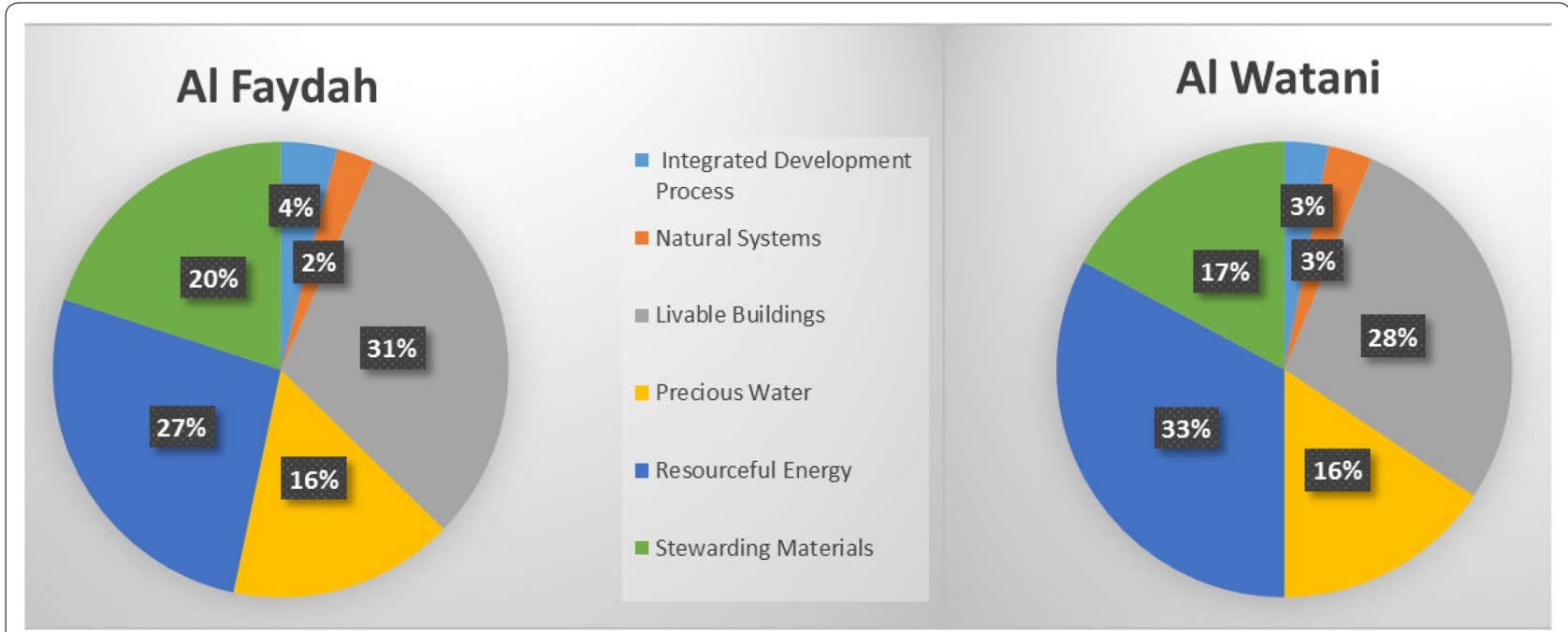

Fig. 10 The percentage ratio of credit points according to Estidama PBRS V1.0 for the studied state housing complexes

satisfaction and is also related to the quality of the environment, noise level, traffic density, as well as the lack of public participation and necessary services and facilities. All these negative factors were considered when designing facilities studied in this paper.

Examination of the impact caused by socio-environmental factors on community satisfaction in different districts of Delhi (Karuppannan and Sivam 2011) showed that it becomes higher when houses are placed around a public place or common open space. The provision of well-located open spaces and good access to public infrastructure play a crucial role in increasing urban sustainability, which is taken into account in the Estidama rating system. Similar results were obtained in the works (Winston 2017; Al Shawabke et al. 2020).

\section{Conclusions}

This study assesses the level of satisfaction with public housing offered by the UAE government to citizens, by the physical characteristics and traditional social aspects of the housing unit, urban design, and social environment in the residential area, whereas also their contribution to overall satisfaction, on the example of two completed government projects in Abu Dhabi, namely, Al Faydah and $\mathrm{Al}$ Watani.

According to the research results, the following conclusions can be drawn:

1. The overall level of satisfaction of residents in these complexes was estimated as high and average. A study of various influencing factors shows that the satisfaction level of $40-60 \%$ of residents is most affected by the good performance of the housing, its layout, and interior decoration. The lowest satisfaction rate of $11-12 \%$ was established for the factor of accessibility and the location of the building in the complex.

2. The state housing projects in the UAE can be considered as acceptable for the comfortable life of residents with a high and average level of satisfaction, which fully meets the needs in terms of physiological, social, economic, and environmental characteristics.

3. The application of the Estidama rating system for public housing construction fully meets the requirements and the expectations of residents although it requires control over each stage of work.

The results obtained are of great scientific significance and can be used in future research efforts.

\section{Authors' contributions}

The author read and approved the final manuscript.

\section{Funding}

This research did not receive any specific grant from funding agencies in the public, commercial, or not-for-profit sectors.

\section{Availability of data and materials}

Data will be available on request.

\section{Competing interests}

The authors declare that they have no competing interests.

\section{Appendix A}

Resident satisfaction survey

Resident job:

Resident job timing:

Family members number: 
Number of kids:

Kids ages:

Resident unit type

\begin{tabular}{llllll}
\hline & $\begin{array}{c}\text { Strongly } \\
\text { disagree }\end{array}$ & Disagree & Neutral & Agree & $\begin{array}{l}\text { Strongly } \\
\text { agree }\end{array}$ \\
\hline $\begin{array}{l}\text { I feel comfortable in } \\
\text { my Unit }\end{array}$ & 1 & 2 & 3 & 4 & 5 \\
$\begin{array}{l}\text { I feel safe in my Unit } \\
\text { I enjoy spending }\end{array}$ & 1 & 2 & 3 & 4 & 5 \\
$\quad$ time in my Unit & & 2 & 3 & 4 & 5 \\
$\begin{array}{l}\text { My Unit has } \\
\text { adequate light }\end{array}$ & 1 & 2 & 3 & 4 & 5 \\
$\begin{array}{c}\text { My Unit has the } \\
\text { required privacy }\end{array}$ & 1 & 2 & 3 & 4 & 5 \\
$\begin{array}{l}\text { My family members } \\
\text { feel satisfied with } \\
\text { the new Unit }\end{array}$ & 1 & 2 & 3 & 4 & 5 \\
\end{tabular}

Do you have separate room to finish your work or spend individual time

YES NO

Do you have enough space for large numbers of guests?

YES NO

Do you need extra space for family members to spent some nights at your home?

Is there continues maintenance arranged to your unit?

YES NO

Do you think your Unit satisfy your needs?

YES NO

YES NO

\section{Comments:}

\begin{tabular}{lll}
\hline & \\
\hline & & \\
\hline & & \\
\hline & & \\
\hline $\begin{array}{l}\text { Any modifications have been done } \\
\text { by the resident to the unit? }\end{array}$ & YES & NO \\
If yes, what kind? & & \\
Do you keep windows opened in & YES & NO \\
Do you use blinded curtains or & Blinded & Normal \\
normal ones? & & \\
$\begin{array}{l}\text { Do you hear noise from your neigh- } \\
\text { bors? }\end{array}$ & YES & NO \\
How do you collect your Unit trash? & Big trash units & Manual collection \\
$\begin{array}{l}\text { Are there segregation trash units } \\
\text { nearby? }\end{array}$ & YES & NO \\
\hline
\end{tabular}

Public spaces (Park, School, Hospital, Sports, Services, (.........).

\begin{tabular}{llllll}
\hline & $\begin{array}{c}\text { Strongly } \\
\text { disagree }\end{array}$ & Disagree & Neutral & Agree & $\begin{array}{c}\text { Strongly } \\
\text { agree }\end{array}$ \\
\hline $\begin{array}{c}\text { I enjoy the public } \\
\text { areas of the com- } \\
\text { pound }\end{array}$ & 1 & 2 & 3 & 4 & 5 \\
$\begin{array}{l}\text { I enjoy various } \\
\text { activities in the } \\
\text { Public areas }\end{array}$ & 1 & 2 & 3 & 4 & 5 \\
$\begin{array}{l}\text { I am comfortable } \\
\text { eating outdoor in } \\
\text { the Public areas }\end{array}$ & 1 & 2 & 3 & 4 & 5 \\
$\begin{array}{c}\text { Sports services are } \\
\text { available in the } \\
\text { public areas }\end{array}$ & 1 & 2 & 3 & 4 & 5 \\
$\begin{array}{l}\text { I can leave my kids } \\
\text { safe in the public } \\
\text { garden }\end{array}$ & 1 & 2 & 3 & 4 & 5 \\
$\begin{array}{l}\text { I feel safe dropping } \\
\text { my kids to school }\end{array}$ & 1 & 2 & 3 & 4 & 5 \\
$\begin{array}{l}\text { It's easy to go near } \\
\text { hospital }\end{array}$ & 1 & 2 & 3 & 4 & 5 \\
\hline
\end{tabular}

\section{Comments:}

\section{My favourite thing about [Unit Design] is:}

If I could change one thing about [Unit Design] it would be:

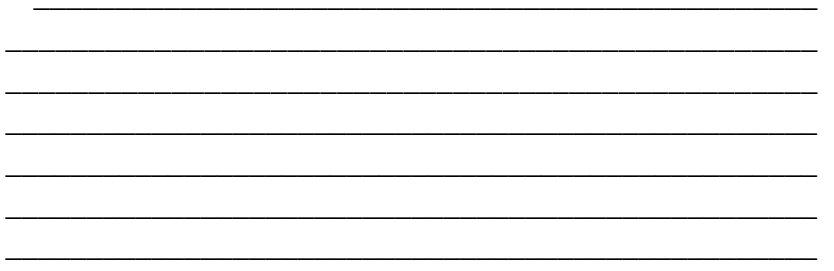

Received: 28 September 2020 Accepted: 29 November 2020

Published online: 07 December 2020 


\section{References}

Abu Dhabi urban planning council (2010) Pearl building rating system: design \& construction, Version 1.0, April 2010. https://www.solarthermalwor Id.org/sites/default/files/news/file/2015-05-04/estidama_constructi on_rating_certificate.pdf. Accessed 30 June 2018.

Ahmed KG (2017) Designing sustainable urban social housing in the United Arab Emirates. Sustainability 9(8):1413

Al Shawabke RK, Alzouby AM, Rjoub A, Alsmadi M, AlKhamaiseh M, Shboul D, Smadi A, Al-Bzour A, Al-Omari R, Alobaidat E (2020) Evaluating the satisfaction rate for affordable housing in non-gated residential area (NGR): the case of Al-Sharq housing project in Zarqa-Jordan. Int J Hous Mark Anal Emerald, Bingley (in press)

Al-Momani AH (2000) Structuring information on residential building: a model of preference. Eng Constr Archit Manag 7(2):179-190

Ali MM (2010) Sustainable urban life in skyscraper cities of the 21st century. Sustain City VI Urban Regener Sustain 129:203-214

Alobaidi KA, Rahim ABA, Mohammed A, Baqutayan S (2015) Sustainability achievement and estidama Green building regulations in Abu Dhabi vision 2030. Mediterr J Soc Sci 6(4):509-518

Anderson MB (2016) New urbanism. International encyclopedia of geography: people, the earth environment and technology. Wiley-Blackwell, New York, pp 1-3

Awadh O (2017) Sustainability and green building rating systems: LEED, BREEAM, GSAS and Estidama critical analysis. J Build Eng 11:25-29

Buys L, Miller E (2012) Residential satisfaction in inner urban higher-density Brisbane, Australia: role of dwelling design, neighbourhood and neighbours. J Environ Plan Manag 55(3):319-338

Chan AP, Adabre MA (2019) Bridging the gap between sustainable housing and affordable housing: The required critical success criteria (CSC). Build Environ 151:112-125

Dempsey N, Bramley G, Power S, Brown C (2011) The social dimension of sustainable development: defining urban social sustainability. Sustain Dev 19(5):289-300

Dizdaroglu D, Yigitcanlar T (2016) Integrating urban ecosystem sustainability assessment into policy-making: Insights from the Gold Coast City. J Environ Plan Manag 59(11):1982-2006

Dohr JH, Portillo M (2011) Design thinking for interiors: Inquiry, experience, impact. Wiley, New York

Higley RC (2008) "Other" processes of rural gentrification and counter-urban migration. University of Brighton, Brighton

Howley P, Scott M, Redmond D (2009) Sustainability versus liveability: an investigation of neighbourhood satisfaction. J Environ Plan Manag 52(6):847-864

Hussein WHA (2019) Development and sustainability of residential communities (neighbourhoods) in Egypt, recommended criteria and indicators drawn from international trials. Urban Reg Plan 4(3):100-108

Ingrao C, Messineo A, Beltramo R, Yigitcanlar T, loppolo G (2018) How can life cycle thinking support sustainability of buildings? Investigating life cycle assessment applications for energy efficiency and environmental performance. J Clean Prod 201:556-569

loppolo G, Cucurachi S, Salomone R, Shi L, Yigitcanlar T (2019) Integrating strategic environmental assessment and material flow accounting: a novel approach for moving towards sustainable urban futures. Int J Life Cycle Assess 24(7):1269-1284

Karji A, Woldesenbet A, Khanzadi M, Tafazzoli M (2019) Assessment of social sustainability indicators in mass housing construction: a case study of Mehr housing project. Sustain Cities Soc 50:101697

Karuppannan S, Sivam A (2011) Social sustainability and neighbourhood design: an investigation of residents' satisfaction in Delhi. Local Environ 16(9):849-870

Kohon J (2018) Social inclusion in the sustainable neighborhood? Idealism of urban social sustainability theory complicated by realities of community planning practice. City Cult Soc 15:14-22
Lee E, Park NK (2010) Housing satisfaction and quality of life among temporary residents in the United States. Hous Soc 37(1):43-67

Lichtenstein S, Badu E, Owusu-Manu DG, Edwards DJ, Holt GD (2013) Corporate social responsibility architecture and project alignments. J Eng Des Technol 11(3):334-353

Liu AM (2003) The quest for quality in public housing projects: a behaviour-tooutcome paradigm. Constr Manag Econ 21(2):147-158

Liu AM, Fellows R, Tuuli MM (2011) The role of corporate citizenship values in promoting corporate social performance: towards a conceptual model and a research agenda. Constr Manag Econ 29(2):173-183

Lopez R (2010) Sense of place and design. Focus 6(1):46-52

Mohit MA, Nazyddah N (2011) Social housing programme of Selangor Zakat Board of Malaysia and housing satisfaction.J Hous Built Environ 26(2):143-164

Ogu VI (2002) Urban residential satisfaction and the planning implications in a developing world context: the example of Benin City, Nigeria. Intern Plan Stud 7(1):37-53

Patricios NN (2002) Urban design principles of the original neighbourhood concepts. Urban Morphol 6(1):21-36

Plan Al Ain 2030 Urban Structure Framework Plan (2015) http://faculty.uaeu. ac.ae/abintouq/GEO_Fall_2015/PlanAIAin2030.pdf. Accessed 12 Dec 2018.

Rahman NA, Ab Manan NA, Saad NL, Abdullah K, Soffian NSM, Ahmad AL (2018) Public facilities guidelines calculator for sustainable housing development. J Inov Malays 1(2):125-144

Riazi M, Emami A (2018) Residential satisfaction in affordable housing: a mixed method study. Cities 82:1-9

Roufechaei KM, Bakar AHA, Tabassi AA (2014) Energy-efficient design for sustainable housing development. J Clean Prod 65:380-388

Saiedlue S, Hosseini SB, Yazdanfar SA, Maleki SN (2015) Enhancing quality of life and improving living standards through the expansion of open space in residential complex. Procedia-Soc Behav Sci 201:308-316

Sakip SRM, Johari N, Salleh MNM (2012) Sense of community in gated and non-gated residential neighborhoods. Procedia-Soc Behav Sci 50:818-826

Shach-Pinsly D (2019) Measuring security in the built environment: evaluating urban vulnerability in a human-scale urban form. Landsc Urban Plan 191:103412

Shawket IM (2018) Identity in urban spaces of residential compounds: contributing to a better environment. HBRC J 14(2):235-241

Teck-Hong T (2012) Housing satisfaction in medium-and high-cost housing: the case of Greater Kuala Lumpur Malaysia. Habitat Int 36(1):108-116

Van Kamp I, Leidelmeijer K, Marsman G, De Hollander A (2003) Urban environmental quality and human well-being: towards a conceptual framework and demarcation of concepts; a literature study. Landsc Urban Plan 65(1-2):5-18

Wagner SL, Shubair MM, Michalos AC (2010) Surveying older adults' opinions on housing: recommendations for policy. Soc Indic Res 99(3):405-412

Walton D, Murray SJ, Thomas JA (2008) Relationships between population density and the perceived quality of neighbourhood. Soc Indic Res 89(3):405-420

Watani Housing Project (2015) https://www.emaratalyoum.com/local-section/ other/2015-05-27-1.788076. Accessed 30 June 2018

Winston N (2017) Multifamily housing and resident life satisfaction in Europe: an exploratory analysis. Hous Stud 32(7):887-911

Wongbumru T, Dewancker B (2016) Post-occupancy evaluation of user satisfaction: a case study of "old" and "new" public housing schemes in Bangkok. Archit Eng Des Manag 12(2):107-124

\section{Publisher's Note}

Springer Nature remains neutral with regard to jurisdictional claims in published maps and institutional affiliations. 